the worse the bleeding became. I therefore decided to perform supra-vaginal hysterectomy; the uterine arteries were ligatured on each side outside the uterus, and then the body of the uterus was cut away. A large pair of Wells's forceps was left on, but the surface of the stump oozed rather freely, and two silk ligatures were passed right and left from before backwards and tied firmly to check it. Some iodoform gauze was packed over the stump, a smail piece being left sticking out at the lower end of the wound. A Keith's tube was inserted and the remainder of the wound closed in the usual way. The re-opening of the wound and the various measures that were required to permanently control the bleeding had occupied a considerable time, and, besides, a good deal of blood had been lost, taking into consideration what was extravasated in the abdomen by the extra-uterine sac before operation, and also reckoning the amount that was lost from the superficial tears on the back of the uterus. How these were produced I am unable to say positively. My impression is, however, that some of the masses of clot removed were partially adherent to the uterus, and that in removing them the peritoneal coat of the uterus nust have been slightly torn, and then the tissues were so friable that almost any kind of manipulation-sponging, pulling up the uterus, and the like-seemed to increase the laceration and the hæmorrhage. At all events, at the end of the operation, when the patient was put back to bed, her face was quite white, her lands and feet quite cold, and no pulse could be felt at the wrist ; and I have no doubt whatever that had she been left without further treatment she would certainly have died, probably without regaining consciousness at all. I decided, however, to try the effect of injecting salt solution into the veins. Our stock of boiled water had been exhausted in washing out the abdomen during the operation, so that the water used in making the salt solution for intravenous injection was merely the water out of the kettle and out of the tap. The salt solution, however, was sterilised, because we keep a concentrated solution of it which is carefully prepared and boiled before each operation. A glass reservoir was filled with salt solution at the temperature of $100^{\circ} \mathrm{F}$. and containing a drachm of common salt to each pint. The injection was made into the median cephalic vein of the left arm, the necessary pressure being obtained simply by hanging up the glass reservoir on the wall about three feet above the patient's head. After one pint had been injected the patient's pulse at the wrist could be felt. After four pints had been injected the pulse was as good as it had been before the operation. The patient made a good recovery. I have seen her several times since she left the hospital ; the abdominal wound is soundly healed, and she remains quite well.

Harley-street, w.

\section{ON THE APPLICATION OF THE SERUM TEST TO THE DIFFERENTIAL DIA- GNOSIS OF TYPHOID AND MALTA FEVER,}

AND ON THE FURTHER APPLICATION OF THE METHOD OF SERUM DIAGNOSIS TO THE ELUCIDATION OF CERTAIN PROBLEMS IN CONNEXION WITH THE DURATION OF IMMUNITY AND THE GEOGRAPHICAL DISTRIBUTION OF DISEASE.

BY A. E. WRIGHT, M.D. DuB , PROFESSOR OF PATHOLOGY, ARMY MEDICAI SCHOOL, NETLEY, AND

SURGmON-Captain F. SMITH ARMY MEDICAL STAFF.

IT is notorious that every clinician in tropical and subtropical countries is constantly meeting cases of continued fever of which he finds it impossible to say whether they are cases of typhoid fever, of Malta fever, of malarial fever, or of some other (possibly as yet undescribed) variety of continued fever. In cases of this kind, and further in cases where it is desirable that a diagnosis should be arrived at early in the course of the disease, the prompt and accurate methods of diagnosis which medical research has recently placed at our disposal will be everywhere welcomed. Three of such methods of diagnosis are at present available. In the first place, the blood may be examined microscopically with a view to determining the presence or absence of pathogenic micro-organisms. This method is of particular utility in connexion with the determination of the presence or absence of the micro-organisms of malaria and of spirillum fever. In the second place, the excretions (and, in particular, the urine $^{1}$ ) may be examined by appropriate cultivation methods with a view to determining the presence or absence of pathogenic micro-organisms. This method is applicable to typhoid fever. It is probably also applicable to Malta fever. Lastly, the method of serum diagncsis may be applied. By this method the blood of a patient who is suffering, or who has suffered, from a continued fever is tested in turn with any pathogenic micro-organisms that may be available, and in particular with the micro-organisms which are causally associated with typhoid fever and Malta fever. We have recently been applying this serum test to the diagnosis, and especially to the after-diagnosis, of tropical and zub-tropical continued fevers. Convalescents from these fevers come under observa. tion in Netley in the persons of soldiers and others who are invalided home from military stations abroad.

\section{METHODS}

Blood is readily obtained in sufficient quantities from the finger tip by puncturing the back of the finger near the nail. It is then drawn off into a pipette, such as is repre sented in Fig. 1. This pipette is converted into a blood capsule by sealing it in the flame at the points indicated in the figure by the letters $x x$. After twenty four hours, or as soon as the blood has duly separated into serum and clot, the ends of the blood capsule are broken off and the separated serum is drawn off by a capillary pipette, as indicated in Fig. 2. The amount of serum which is drawn off is indicated by placing a mask $y$ on the outside of the capillary pipette. The serum is then blown out into a watch glass and is diluted first fivefold by filling up the capillary pipette four times in succession with normal salt solution and by blowing this salt solution out isto the serum in the watch glass. In this manner any desired diluticns are obtained. It is convenient to make 5-, 10-, 25-, 50-, and 100-fold cillutions of each sample of serum.

Having diluted the'serum in this manner a small quantity of the diluted serum is allowed to run up into the stdimentation tube ${ }^{2}$ represented in the diagram by Fig. 3 . For the sake of clearness let it be supposed that diluted serum has been allowed to run up the tube to the pcint indicated by the letter $a$ in Fig. 3. This point is now indicated on the outside of the sedimentation tube by a red mark. Having filled in the tube in this manner with the desired amount of diluted serum, the point of the capillary pipette is now turned upwards, so as to admit a bubble of air into the point of the capillary pipette. The diluted serum now occupies the position indicated in Fig. 3 by the space $c$ to $d$, the bubble occupying the space between the letters $b$ and $c$. Having thus introduced our bubble of air, which is to serve the purpose of an index, the end of the capillary pipette is immersed into a perfectly fresh emulision made from a young culture of either typhoid or, as the case may be, Malta fever bacteria. The emulsion is allowed to run in until it reaches the point $a$. We have now introduced an equal quantity of diluted serum and of typhoid or Malta fever emulsion into our sedimentation tube. The next step is to mix the bacterial emulsion with our diluted serum. This is easily done by aspirating by means of the indiarubber tube $T$ the contents of the capillary pipette two or three times in succession into the mixing chamber $z$. Having thus obtained an intimate mixture of an equal portion of the diluted serum and of the bacterial emulsion, we blow the contents of the tube down into the stem of the pipette, taking care not to blow it down too near the end of the pipette, and we seal the point of the pipette in the flame. We then label the capillary pipette 1 in 10, if we have mixed an equal volume of 5 -fold diluted serum with a bacterial emulsion: 1 in 20 , if we have employed a 10 -fold diluted serum, and so on. We then put up a control tube of the bacterial emulsion

I The importance both from a diagnostic and a hygienic point of view of recognising the presence of typhoid bacilli in the urine was pointed out in a paper which was wricten by one of us in conjunction with Surgeon-Major Semple (THE LaACE'I, July 27th, 1896). The results which were arrived at in that paper bave been recently confirmed and somewhat extended by Dr. P. Horton Smith (Royal Medical and Chirurgical Society, Feb. 7th, 1897)

Mr. A. E. Dean, jun., 73, Hatton-garden, E.C., is, at my suggestion, making sero-sedimentation tubes of stout glass. Prorision is made in these tubes for preventing the escape of the contents when the tubes are placed upright so as to allow of sedimentation. 
mixed with normal serum or with salt solution, and finally we place the whole series of sedimentation tubes upright in an ordinary test-tube labelled with the name of the patient and the date. Figs. 4 and 5 represent such capillary pipettes after the lapse of twenty-four hours. In Fig. 4 the dark shading seen at $x$ represents a pellet of either typhoid or Malta fever bacteria which have been immobilised and agglomerated by a serum from a person who is undergoing, or who has undergone, the specific fever which corresponds to the variety of bacteria which have been employed. Fig. 5 represents the control pipette which in the case of the eminently motile Malta fever or typhoid bacteria remains evenly turbid.

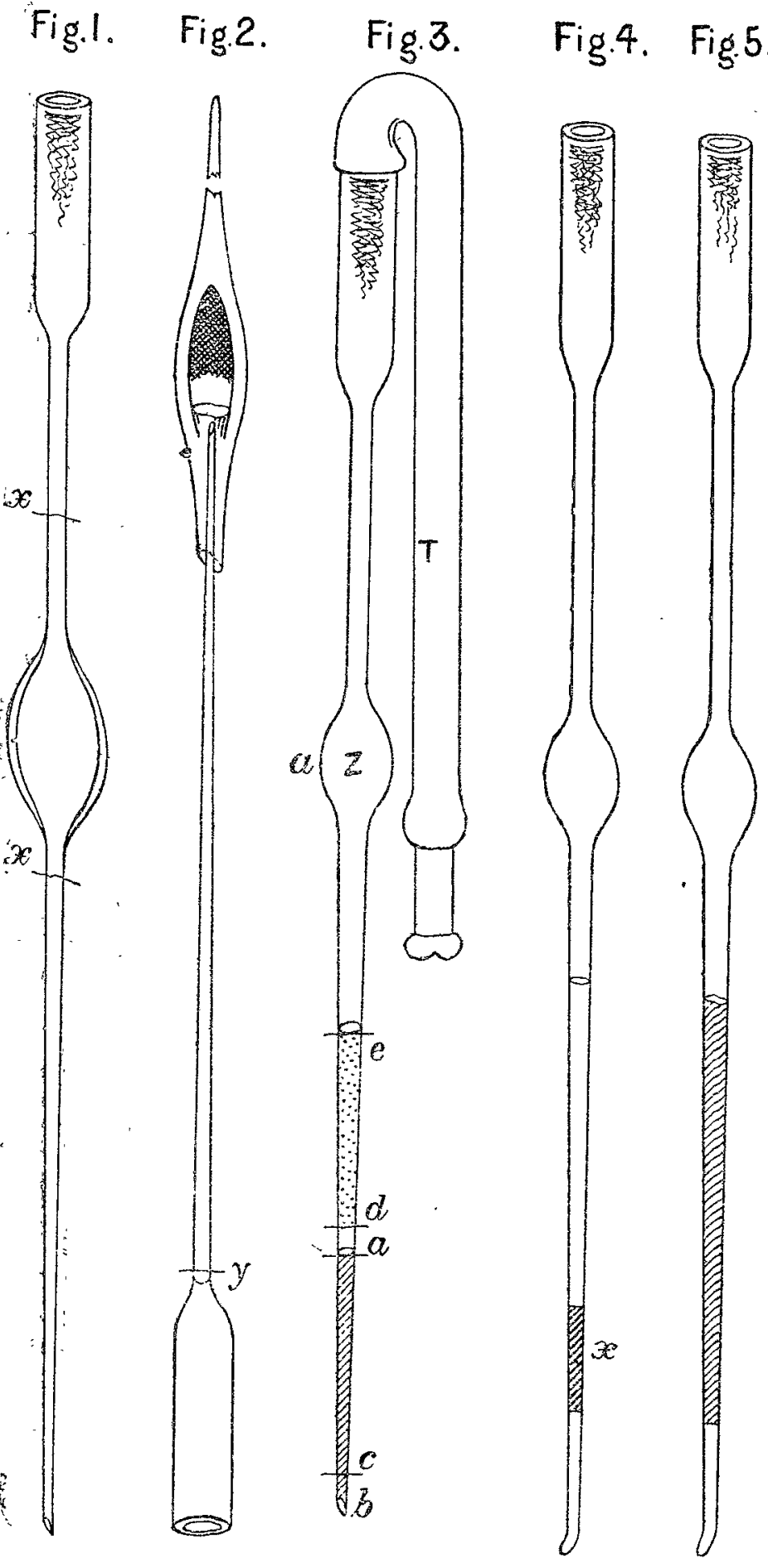

Fig. 1. Capillary pipette for drawing off blood from finger. Fig. 2. Method of drawing off serum from blood capsule. Fig. 3. Sedimentation tube tilled in and ready for mixing. ing. 4. Sedimentation effect produced by specific serum. The pellet of agglomerated bacteria is seen at $x$ the superis seen at bottom of tube; the fluid is not clarified.

Examples of the application of the method.-The following are typical examples of the application of the method of serum diagnosis to the differentiation of Malta fever from typhoid fever.

Example I.-Sergeant $L$ - of the Medical Staff Corps, arrived from Aldershot in October, 1896, having been detailed for duty at Netley. A few days after arrival at Netley the patient "reported sick" and was admitted to hospital with a recrudescence of a fever from which he had suffered some months before. His papers showed that this fever had been diagnosed to be typhoid fever. The patient's serum showed absolutely no reaction with the bacillus typhosus. His serum in 10-, 25-, 50-, 100-, and 200-fold dilutions showed a very marked reaction with the micrococcus Melitensis of Bruce. Inquiry into the patient's history revealed that when he went into hospital at Aldershot he had only recently returned from Gibraltar.

Example II.-Sergeant $F_{-}-$, of the Medical Staff Corps. The patient was admitted to hospital in Malta on Oct. 2nd, 1896. He died in hospital on Nov. 20th. Some of his symptoms, such as diarrhœa associated with blood in the stools, were suggestive of typhoid fever. The necropsy, however, showed only slight ulceration of the colon, and the absence of any implication of Peyer's patches. In the light of the facts, his case was diagnosed as having in all probability been a case of Malta fever.

A stitosnn of the above, aged nine years, contracted fever in Malta and died at the end of November after ten days illness. The case was diagnosed as probably one of typhoid fever.

Another stepson, aged seven and a half years, contracted ferer in Malta at the beginning of last December, and was immediately invalided home. Doubts were expressed in his papers as to whether the case was one of Malta fever or of typhoid fever. He is now quite convalescent. His serum gives an absolutely negative reaction with the micrococcus Melitensis, but gives a very marked efrect in 10-, 25., 50 -, a 100 fold dilutions with the bacillus typhosus.

The wife of Sergeant $F$ - contracted fever in Malta in the month of September. She was in bed for ten days. The serum gives an absolute'y negative reaction with the bacillua typhosus. The serum, however, gives in 10., 25-, and 50 . fold-but not in 100 fold-dilutions a characteristic reaction with the micrococcus Melitensis.

A child of $\mathcal{S}_{\mathrm{r}}$ geant $F-$, a girl aged three years, contracted fever in Malta in May, 1896. She suffered severely from fever till the end of September, 1896. She is now quite convalescent. Her serum gives absolutely no reaction with the bacillus typhosus, but the seram in 10-, 25-, 50-, 100-, and 200-fold dilutions gives very marked reaction with the micrococcus Melitensis.

It will be obvious how very difficult a clinical problem was presented by this last series of cases, and how very easily clinical problems of this kind can be re-solved by the employment of the methnd of serum diagnosis.

Example III.-Private P-_ (at present under treatment in Netley), invalided home from India for secondary syphilis He has suffered for the last four months from a continuous but very irregular fever, which has some resemblance to to the typical curve of Malta fever. Examination of history discloses that the patient left Enoland in March, 1892, for Gibraltar. He continued in good health until the autumn of that year, when he was attacked with continued fever, which, from its long duration (103 days in hospital) and from the fact that the patient was constipated throughout, may not unreasonably be assumed to have been Mediterranean fever. The patient left Gibraltar for India with his regiment in December, 1893, feeling perfectly well. In India he was noted as having suffered occasionally from attacks of fever. These attacks of fever were, however, not severe enough to require treatment in hospital. The patient began to suffer again from fever very socn after he was put under orders for home. His blood has been examined by us with negative results for malaria, and his urine has recently been examined by us with negative results both for the presence of typhoid and Malta fever micro-organisms. His serum exerts no influence upon the bacillus typhosus. It manifests, even in 1000 . fold dilution, a very characteristic effect upon the micrococcus of Malta fever. It is fovious that the interpretation of the results of serum-diagnosis was here complicated by the fact that the patient has presumably suffered some four years ago from Malta fever, and that a reaction with the micrococcus of Malta fever might possibly have persisted for this period. In view, however, of the fact that the serum shows the specific reaction in such an enormous dilution, and, further, in view of the fact that four years have elapsed since he suffered from fever in Gibraltar, and lastly, in view of the fact that the patient is now suffering from pains in the joints, it seems to us practically certain that this patient is suffering from Malta fever.

3 Our experience with monkeys has shown us that the specific reaction to the micrococcus Meliteinsis is generaliy already present on reaction to the micrococcus

4 The question of greatest clinical interest in connexion with this case is, of course, the question whether the patient was re-infected with Malta fever in India, or whether the attacks of fever from which he uffered at intervals in India were mere recrulescences of his original 
Having sufficiently illustrated this last point we may now subjoin in tabular form the results which we have obtained by the application of this method of serum diagnosis.

The results which are tabulated below were obtained by testing the reaction of the serum in the capillary serosedimentation pipettes which have been described and illus. trated above.

In the tables which are subjoined a voluminous sedimentation is indicated by the sign +; a slighter but still perfectly characteristic sedimentation is indicated by the sign *; a negative result is indicated by the sign 0.

TABLE I._Cases Diagnosed as "Malta Fever" which shoned Reaction on the Micrococcus Melitensis of Bruce. ${ }^{\overline{3}}$

\begin{tabular}{|c|c|c|c|c|c|c|c|}
\hline \multirow{2}{*}{$\begin{array}{l}\text { No. of } \\
\text { case. }\end{array}$} & \multicolumn{2}{|c|}{$\begin{array}{l}\text { Period elapsed } \\
\text { since illness. }\end{array}$} & \multicolumn{5}{|c|}{ Degree in which serum was diluted. } \\
\hline & Years. & Months & 1 in 10. & 1 in 25. & 1 in 50. & 1 in 100 & 1 in 200. \\
\hline $1 j$ & - & 5 & * & * & $*$ & 0 & 0 \\
\hline $2_{ \pm}^{+}$ & - & 6 & + & + & + & - & - \\
\hline 3 & - & 6 & + & + & + & + & + \\
\hline 4 & - & 8 & + & + & + & + & + \\
\hline 5 & 1 & 8 & + & + & + & + & + \\
\hline B! & 1 & 9 & + & + & + & + & + \\
\hline 7 & 3 & $1-$ & + & $\because$ & $*$ & 0 & 0 \\
\hline $8 \$$ & Nor & will. & + & + & + & + & + \\
\hline
\end{tabular}

TABLE II.-Cases diagnosed "Iyphoid Fever" which showed Reaction on Typhoid Bacillus.

\begin{tabular}{|c|c|c|c|c|c|c|c|}
\hline \multirow{2}{*}{$\begin{array}{c}\text { No. } \\
\text { of } \\
\text { case. }\end{array}$} & \multicolumn{2}{|c|}{$\begin{array}{c}\text { Period elapsed } \\
\text { since illness. }\end{array}$} & \multicolumn{5}{|c|}{ Degree in which the Serum was diluted. } \\
\hline & Years. & Months & 1 in 10. & 1 in 25. & 1 in 50. & 1 in 1 co. & 1 in $2 \mathrm{CO}$. \\
\hline 1 & - & 5 & + & + & * & 0 & 0 \\
\hline 2 & - & 6 & * & * & 0 & 0 & 0 \\
\hline $\mathfrak{3}$ & 一 & 6 & + & + & + & + & + \\
\hline $4 \dagger$ & - & 6 & + & + & + & - & - \\
\hline 5 & - & 6 & $*$ & * & 0 & 0 & 0 \\
\hline 6 & - & 7 & * & * & 0 & 0 & 0 \\
\hline $7 \dagger$ & - & 9 & + & + & + & - & - \\
\hline 8 & - & 9 & + & $*$ & 0 & 0 & 0 \\
\hline 9 & - & 10 & + & * & 0 & 0 & 0 \\
\hline 10 & 1 & 2 & $*$ & * * & 0 & 0 & 0 \\
\hline 11 & 1 & 8 & + & + & * & 0 & 0 \\
\hline 12 & 2 & - & + & * & 0 & 0 & 0 \\
\hline $13 \vec{r}$ & 6 & - & + & + & - & - & - \\
\hline 14 & 6 & - & + & * & 0 & 0 & 0 \\
\hline 15 & 12 & - & $*$ & $*$ & 0 & 0 & 0 \\
\hline
\end{tabular}

$\dagger$ Higher dilutions not tried.

TABLE IIL.-Cuses diagnosed "Typhoid Ftver" which had no effect on the Typhoid Bacillus, but showed a distinot Reaction on the Malta Fever Mroroesccus.

\begin{tabular}{|c|c|c|c|c|c|c|c|c|}
\hline \multirow{2}{*}{$\begin{array}{c}\text { No. } \\
\text { of } \\
\text { case. }\end{array}$} & \multirow{2}{*}{$\begin{array}{l}\text { Place in which } \\
\text { illness } \\
\text { occurred. }\end{array}$} & \multirow{2}{*}{\multicolumn{2}{|c|}{$\overbrace{\text { Years. Months }}^{\begin{array}{c}\text { Period elapsed } \\
\text { since illness. }\end{array}}$}} & \multicolumn{5}{|c|}{$\begin{array}{l}\text { Degree to which the serum } \\
\text { was diluted. }\end{array}$} \\
\hline & & & & $\begin{array}{l}1 \text { in } \\
10 .\end{array}$ & $\begin{array}{c}1 \text { in } \\
25 .\end{array}$ & $\begin{array}{c}1 \text { in } \\
50 .\end{array}$ & $\begin{array}{l}1 \mathrm{in} \\
100\end{array}$ & $\begin{array}{l}1 \text { in } \\
200 .\end{array}$ \\
\hline 1 & Aldershot. & - & 9 & + & + & + & $T$ & + \\
\hline $2^{*}$ & Sabathu, India. & - & 7 & + & + & + & + & + \\
\hline $3^{*} \dagger$ & Ditto. & - & 7 & + & - & $\cdots$ & - & - \\
\hline
\end{tabular}

* India was the only foreign station in which the patient had served. $\dagger$ Higher dilutions not tried.

with Surgeon-Major Semple, elicited on the survival of the micrococcus Melitensis in the spleen of monkeys who have perfectly recovered from Malta fever, both these interpretations appear to us to be equally admissible.

5 We are deeply indebted to Surgeon-Captain L. Hughes for sending us a culture of this micro-organism. The culture which was sent to as was obtained in Malta from a fatal case of the disease.
TABLE IV.-Cases Diagnosed "Typhoid Fever" which shonea"

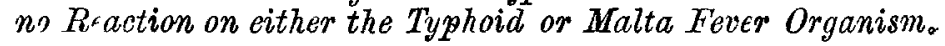

\begin{tabular}{|c|c|c|c|}
\hline \multirow[t]{2}{*}{ No. of case. } & \multirow{2}{*}{$\begin{array}{l}\text { Place in which illness } \\
\text { occurred. }\end{array}$} & \multicolumn{2}{|c|}{$\begin{array}{l}\text { Period elapsed since } \\
\text { illness. }\end{array}$} \\
\hline & & Years. & Months. \\
\hline $1,2,3$, and 4 & Sabathu, India. & - & $8,8,6$, and 6 \\
\hline 5 & Nowshera, India. & - & 7 \\
\hline 6 & Lucknow, India. & - & 10 \\
\hline 7 & Line of march, India. & - & 3 \\
\hline 8 & Rangoon, Burmah. & - & 6 \\
\hline 9 & Shwebo, Burmah. & - & 9 \\
\hline 10 & Cannanore, Inơia. & - & 10 \\
\hline 11 & Hong-Kong. & - & 9 \\
\hline 32 & Benares, India. & - & 8 \\
\hline 13 & Umballa, India. & - & 6 \\
\hline 14 & Natal, South Africa. & 17 & 一 \\
\hline
\end{tabular}

TABLE V.-Cases diagnosed "Malarial Fever," or not specifically diagnosed, which showed Reaction on the Malta Fever Organism.

\begin{tabular}{|c|c|c|c|c|c|c|c|c|}
\hline \multirow{2}{*}{ 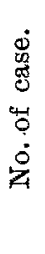 } & \multirow{2}{*}{$\begin{array}{l}\text { Place in which ill. } \\
\text { ness occurred. }\end{array}$} & \multicolumn{2}{|c|}{$\begin{array}{c}\text { Period } \\
\text { elapsed since } \\
\text { illness. }\end{array}$} & & \multicolumn{4}{|c|}{ Sedimenting effect. } \\
\hline & & $\underset{\dot{D}}{\vec{d}}$ & 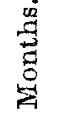 & $\stackrel{0}{0}$ & $\underset{n=1}{\stackrel{2}{a 1}}$ & $\underset{\substack{0 \\
.5}}{.5}$ & 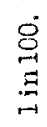 & 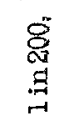 \\
\hline $1 \dagger$ & Nowshera, India & 一 & 11 & + & + & + & + & + \\
\hline 2 & Hong. Kong. & - & 6 & * & $\%$ & 0 & 0 & 0 \\
\hline $3_{+}^{+}$ & Meean-Meer. & No & ill. & + & + & + & + & + \\
\hline
\end{tabular}

$\dagger$ India was the only forejgn station in which the patient had served. + Distinct effect up to 1000 -fold dilution.

TABLE VI._Case diagnosed"Malta Fever" which shoned no Reaction on the Micrococous Melitensis, but which showed a Distinct Elfect on the Typhoid Eacillus.

\begin{tabular}{|c|c|c|c|c|c|c|c|c|}
\hline \multirow{2}{*}{ 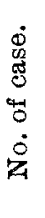 } & \multirow[b]{2}{*}{$\begin{array}{l}\text { Place in which ill- } \\
\text { ness occurred. }\end{array}$} & \multicolumn{2}{|c|}{$\begin{array}{l}\text { Period } \\
\text { elapsed. }\end{array}$} & \multicolumn{5}{|c|}{$\begin{array}{l}\text { Degree to which the serum } \\
\text { was diluted. }\end{array}$} \\
\hline & & 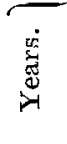 & 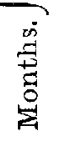 & 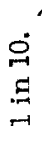 & 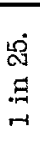 & $\begin{array}{l}0 \\
0 \\
\not \\
ت \\
\vec{H}\end{array}$ & 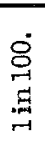 & 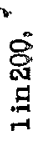 \\
\hline 1 & Maita. & $\begin{array}{l}\text { Ill a } \\
\text { of } \\
\text { na }\end{array}$ & $\begin{array}{l}\text { time } \\
\text { ami- } \\
\text { on. }\end{array}$ & + & $t$ & + & * & 0 \\
\hline
\end{tabular}

A not inconsiderable number of interesting facts are disclosed by a study of these tables. The following are perhaps the more important of these :-(1) Consideration of Table I. discloses the fact that the micrococcus Melitensis, which was discovered by Surgeon-Major D. Bruce, is in reality, as he asserted it to be, the true cause of Malta fever. Out of nine clinically more or less well-characterised cases which were examined by us, the eight which are tabulated here have shown a perfectly characteristic reaction to the micrococcus Melitensis. The only one of the nine cases which failed to react was that of a patient who had suffered from Malta fever five years previously to the date of our examination. We may not unreasonably surmise that the specific power of sedimenting the micro-organisms of Malta fever may, in this case, have passed away. (2) Consideration of Tables III. and V. discloses the fact that Malta fever is, as Bruce and others have long surmised, a disease wbich is not by any means confined to the Mediterranean basin. We have here what we take to be definite evidence of its existence in three stations in Northern India. We have, further, what we take to be probable evidence of its existence in Hong-Kong. (3) Table III. shows that a certain number of cases which are from their clinical symptoms diagnosed to be typhoid fever, axe in reality cases of Malta fever. (4) Table IV. shows that a considerable number of cases which are from their clinical characters diagnosed to be typhoid are in all probability neither cases of typhoid fever nor cases of Malta fever. It is 
possible that the fevers from which these particular patients suffered may have been malarious in character. It is also possible that these fevers may have belonged to some as yet undefined category of continued fever. What is important for us to note is the fact that any tropical fever which is unaccompanied by the presence of malaria parasites in the blood, and which can by the method of serum-diagnosis be shown to be neither typhoid fever nor Malta fever, is a fever which might very profitably be made the subject of bacterio. logical investigation. (5) Tables I. and II. show that the specific agglomerating and sedimenting power, which is acquired by the blood in cases of fever, persists in the blood for a considerable term of years. We have been able to demonstrate its existence in the blood in the case of typhoid fever after no less a period than twelve years. Similarly, we have been able to demonstrate its persistence in the blood for at least three years after an attack of Malta fever.

These facts are of the greatest importance, if, as was urged in a paper on Typhoid Vaccioation which was written by one of us in conjunction with Surgeon-Major D. Semple, the sedimenting and agglomerating power of the blood is in reality a true index of the condition of immunity.

Duration of the immunity against cholera which is conferred by undergoing either an anti-cholera inooulation or an attock of actual cholera. - With a view of further elucidating this question of the association of the sedimenting power of the blood with immunity we have recently examined the blood of one convalescent from (supposed) cholera, and further the blood of five patients who had submitted themselves to Mr. Haffkine's cholera inoculations. The results of these blood examinations are of a certain amount of interest, even though their interpretation is a matter of considerable difficulty and even though they have no very close relation with the question of immunity against septicæmias, such as typhoid fever and Malta fever.

TABLE VII.-A Case Diagnosed "Cholera" and Cases of Cholera Vacuination which showed no Reaction on the Cholera Vibrio."

\begin{tabular}{|c|c|c|c|c|c|c|}
\hline $\begin{array}{c}\dot{0} \\
0 \\
0 \\
0 \\
4 \\
0 \\
\dot{0} \\
\mathbf{z}\end{array}$ & $\begin{array}{l}\text { Place in which } \\
\text { illness or vacci- } \\
\text { nation occurred. }\end{array}$ & \multicolumn{2}{|c|}{$\begin{array}{l}\text { Period elapsed } \\
\text { since illness. }\end{array} \overbrace{\text { Years. Montbs. }}$} & \multicolumn{2}{|c|}{$\begin{array}{l}\text { Period elapsed } \\
\text { since vaccination. } \\
\text { Years. Months. }\end{array}$} & $\begin{array}{l}\text { Result of } \\
\text { the appli- } \\
\text { cation of } \\
\text { the serum } \\
\text { test. }\end{array}$ \\
\hline 1 & Poonab, India. & 一 & 4 & - & - & $\begin{array}{c}\text { Absolutely } \\
\text { negative. }\end{array}$ \\
\hline $2^{*}$ & Dinapore, India. & - & - & 2 & - & , \\
\hline $3 *$ & Poonah, India. & 一 & - & - & 4 & " \\
\hline $4+$ & Poonah, India. & - & - & - & 4 & $"$ \\
\hline 5 & Ranikhet, India. & $\ldots$ & - & 3 & 4 & ", \\
\hline $6^{* \prime \prime}$ & Lucknow, India. & - & - & 3 & 4 & $"$ \\
\hline
\end{tabular}

* Vaccinated in two operations. † Vaccinated in one operation only.

In conclusion we desire to advert to a possible application of the method of serum-diagoosis to the differentiation of the buboes which are due to syphilis or ordinary pyogenic microorganisms, from the buboes which are due to the entrance of the plague bacillus into the body. Necessity for some such method of differentiation arises, first in connexion with the study of the geographical distribution of plague, and secondly in connexion with the early diagnosis of mild cases of plague. This question of the differential diagnosis of buboes seems to us to acquire a certain importance in view of the fact that one of us when Medical Officer of Health for Penang, had occasion to observe and to call attention to the increased number of non-venereal buboes which occurred in Penang very soon after the outbreak of the great epidemic of plague in Hong-Kong.

Netley.

6 Vide Brit. Med. Jour., Jan. 30th, 1897

7 In view of the differences which exist between various rarieties of cholera it is perhaps worth noting that the cholera with which we tested these bloods is a cholera which was kindly placed at our disposal by Profess or Pfeiffer. It is a cholera which shows the perfectly characteristic agglomeration and sedimentation when it is treated with the serum of Pfeiffer's immunised goats.

Isolation Hospital for Blandford, DoRseTsgipe - Lord Portman has promised $£ 500$ towards the erection of an isolation hospital for Blandford, and if necessary will also give the site.

\section{REMARKS UPON VIRTUAL OR RELATIVE MITRAL STENOSIS.}

BY H. D. ROLLESTON, M.D. CantaB., F.R.C.P. LOND., ASSISTANT PHYSICIAN TO ST. GEORGE'S HOSPITAL, AND TO THE VICTORIA hOSPITAL FOR CEILIPBEX, CHELSEA;

$A \mathbb{D}$

W. LEE DICKINSON, M.D. CANTAB., F.R.C.P. LoND., ASSIS FAYT PHISICIAN TU ST. GHORGF'S FOSIPITAL, AND TO THE EOSPITAL FUR SICK CHILI REN, GREAT ORMONI STREET.

ThE objec's of this paper is to draw attention to an occasional state of the mitral valve in which there are all the anatomical characters of stenosis, but on so large a scale that stenosis does not actually exist. The segments are thickered and welded together, and perhaps depressed into the cavity of the ventricle so as to approach the form of a funnel. The passage, however, is absclately as large as, or larger than, natural, though small in relation to the ventricle which is dilated. Clinically, the blowing murmur of mitral regurgitation is always present, and frequently also a more or less typical murmur of the kind called "pre. systolic." Upon first meeting with such a case post mortem the question naturaliy presents itself whether there had not been actual mitral stenosis, till, perhaps only at last, the valve became enlarged as the ventricle dilated. However, it is very improbable that a valve which has once attained an important degree of stenosis and rigidity can afterwards become uniformly enlarged. It is true we sometimes find that valves which obviously have been, and perhaps are still, stenosed have undergone a certain amount of widening from laceration of the segments or rupture of the chordæ tendineæ; but such lesions have generally been produced through the medium of ulceration, and although the ulceration was doubtless invited by strain it is not with such irregular deformities that we are dealing here. A more satisfactory explanation is that the valve, though naturally tending to stenosis, has been held open from the first by the dilatation of the ventricle. In all such cases the disease of the valve and the disease of the ventricle seem to have originated at or about the same time. Most of them are instances of adherent pericardium in young persons, a condition which, arising in the rheumatic pericarditis of childhood, is attended equally by dilatation of the ventricle and mitral endocarditis of that limited kind which, if free to pursue its natural course, would $\epsilon$ nd in stenosis. In others there is aortic regurgitation, the dilatation of the ventricle rewulting from which has evidently overtaken the mitral disease while the valve was yet pliant and extensile, even if the latter set in first. In one of our cases there was neither adherent pericardium nor aortic regurgitation, but the ventricle had been kept dilated by persistence of the same attack of rheumatism which caused the disease of the valve. Under such circumstances, where dilatation of the ventricle is the more acute and violent mischief, the state of the valve we are considering is clearly beneficial. The orifice being fully large does not directly obstruct the circulation in the lungs, while by tending to stenosis it moderates the mitral regurgitation which is always present in these cases and which is free in proportion as the valvular segments yield to the strain. It is preferable, therefcre, to describe the condition as "relative" rather than "virtual" stenosis; the latter term would imply the effects as well as the resemblance of the actual thing. We append an abstract of three illustrative cases from among a dezen of the same kind of which we have taken clinical and post-mortem notes.

CASE 1.-The patient was a girl aged twenty jears. She bad been liable to palpitation for the last two years and œdema of the legs for six months. The impulse of the heart was exten:ive and turbulent. The apex was in the fifth left space far outside the nipple line. At the apex there was an early rough murmur, accompanied by a thrill, ending in a snap, and followed by a blowing systolic murmur. The patient died from pneumonia. At the necrop:y the two layers of the pericardium were found to be completely united by old adhesions. The right auricle was dilated and the right ventricle hypertrophied. The tricuspid and pulmonary valves were healthy. The terminal branches of the pulmonary artery were atheromatous. The left auricle was greatly dilated and had partly compress $\epsilon d$ the left bronchus. The mitral orifice fairly admitted two fingers. The edges of the segments and the 